\title{
Purification and preliminary crystallization of alanine racemase from Streptococcus pneumoniae Ulrich Strych ${ }^{1}$, Milya Davlieva1, Joseph P Longtin ${ }^{1}$, Eileen L Murphy'1, Hookang Im¹, Michael J Benedik² and Kurt L Krause*1,3
}

\author{
Address: ${ }^{1}$ University of Houston, Department of Biology and Biochemistry, 4800 Calhoun Rd, Houston, TX 77204-5001, USA, ${ }^{2}$ Department of \\ Biology, Texas A\&M University, College Station, TX 77843-3258, USA and ${ }^{3}$ Department of Biochemistry, University of Otago, P.O. Box 56, \\ Dunedin, New Zealand \\ Email: Ulrich Strych - strych@uh.edu; Milya Davlieva - milyadav@hotmail.com; Joseph P Longtin - lontjp99@yahoo.com; \\ Eileen L Murphy - eileenandjim@gmail.com; Hookang Im - hookangim@yahoo.com; Michael J Benedik - benedik@tamu.edu; \\ Kurt L Krause* - kurt.krause@stonebow.otago.ac.nz \\ * Corresponding author
}

Published: 17 May 2007

BMC Microbiology 2007, 7:40 doi:10.1 186/147/-2180-7-40
Received: 2 February 2007

Accepted: 17 May 2007

This article is available from: http://www.biomedcentral.com/147I-2/80/7/40

(C) 2007 Strych et al; licensee BioMed Central Ltd.

This is an Open Access article distributed under the terms of the Creative Commons Attribution License (http://creativecommons.org/licenses/by/2.0), which permits unrestricted use, distribution, and reproduction in any medium, provided the original work is properly cited.

\begin{abstract}
Background: Over the past fifteen years, antibiotic resistance in the Gram-positive opportunistic human pathogen Streptococcus pneumoniae has significantly increased. Clinical isolates from patients with community-acquired pneumonia or otitis media often display resistance to two or more antibiotics. Given the need for new therapeutics, we intend to investigate enzymes of cell wall biosynthesis as novel drug targets. Alanine racemase, a ubiquitous enzyme among bacteria and absent in humans, provides the essential cell wall precursor, D-alanine, which forms part of the tetrapeptide crosslinking the peptidoglycan layer.
\end{abstract}

Results: The alanine racemases gene from S. pneumoniae $\left(a \mid r_{S P}\right)$ was amplified by PCR and cloned and expressed in Escherichia coli. The 367 amino acid, 39854 Da dimeric enzyme was purified to electrophoretic homogeneity and preliminary crystals were obtained. Racemic activity was demonstrated through complementation of an alr auxotroph of $E$. coli growing on L-alanine. In an alanine racemases photometric assay, specific activities of 87.0 and $84.8 \mathrm{U} \mathrm{mg}^{-1}$ were determined for the conversion of D- to L-alanine and L- to D-alanine, respectively.

Conclusion: We have isolated and characterized the alanine racemase gene from the opportunistic human pathogen $S$. pneumoniae. The enzyme shows sufficient homology with other alanine racemases to allow its integration into our ongoing structure-based drug design project.

\section{Background}

Streptococcus pneumoniae is a Gram positive diplococcus that colonizes the upper respiratory tract in about $20 \%$ of healthy humans, but is a leading cause of diseases such as otitis media, bacteremia, lobar pneumonia, and meningitis [1], particularly when enclosed in type-specific polysaccharide capsules. Among the elderly, S. pneumoniae is the most common cause of fatal community-acquired pneumonia [2], and in children the most common cause of community-acquired pneumonia, middle ear infections and meningitis [3]. From 1970 to 1990, resistance to $S$. pneumoniae has increased significantly, presumably due to the increased use of antibiotics. The first reports of penicillin-resistant $S$. pneumoniae strains appeared in the US in 
the early-1980s [4], then beginning in the 1990s their share increased from less than $5 \%$ of all isolates to approximately $35 \%$ in 2002 [5]. Similarly, resistance to macrolides is increasing, with $24 \%$ of all isolates being resistant in 2000 [6]. To further complicate the issue, multidrug resistance is increasingly present among $S$. pneumoniae isolates, documented by a recent study showing $22 \%$ of all isolates to be resistant to at least three antibiotics [7].

In light of this growing resistance problem, the identification and characterization of more potential targets for antibiotic therapy is of paramount importance. The inhibition of bacterial growth through antibiotics targeting cell wall biosynthesis has been a proven mode of action since the beginning of the antibiotic era [8]. While penicillin targets the crosslinking reaction in peptidoglycan biosynthesis, there are also choices when it comes to inhibiting the formation of essential precursors for the peptidoglycan layer. One of those precursors, the amino acid D-alanine, is an essential component of the tetrapeptide crosslinking the glycan strands. It is provided through the racemization of the naturally occurring L-alanine, catalyzed by the cytoplasmic enzyme alanine racemase (Alr, EC 5.1.1.1.).

Alr is a pyridoxal 5'-phosphate containing enzyme, ubiquitous among most bacteria, and absent in humans. A lysine residue connected to the PLP cofactor by an internal aldimine bond acts as a base for the conversion of D-to Lalanine while a nearby tyrosine from the second monomer acts as a base for the abstraction of a hydrogen from L-alanine [9]. We have determined crystal structures of alanine racemases from other human pathogens in the past. Notably, the enzymes from Mycobacterium tuberculosis and Pseudomonas aeruginosa have been resolved at high resolution $[10,11]$. Both enzymes are dimers with a similar domain makeup and include both an $\alpha / \beta$-barrel at the $\mathrm{N}$-terminus and a C-terminus primarily made of $\beta$ strands. Because the active site of Alr is small we are interested in identifying conserved residues that regulate the entrance of the substrate into the substrate binding pocket [11] with the goal of developing compounds to control access of substrate to the active site.

This paper describes the molecular cloning, expression, purification, and elucidation of the biochemical properties of the alanine racemase from $S$. pneumoniae. We show evidence that the $a l r_{S P}$ gene encodes a functional alanine racemase through complementation of an E. coli Dalanine auxotroph, and through a specific spectrophotometric assay. We have obtained preliminary crystals of $S$. pneumoniae Alr, and intend to incorporate the enzyme into our ongoing structure-based drug design program $[12,13]$. Determining the structure of $\mathrm{Alr}_{\mathrm{SP}}$ is an essential prerequisite for the development of an accurate pharmacophore model of the enzyme. Using our structure will allow us to conduct molecular dynamics simulations to obtain information about the different conformations of the enzyme (and its substrate), eventually yielding a dynamic pharmacophore model. Using in silico methods, compounds from the Available Chemicals Directory [14] that fit the pharmacophore model will be identified and submitted to experimental testing, first in vitro and subsequently in vivo. Proof of principle has been provided by our collaborators at the University of Houston for the alanine racemase from G. stearothermophilus [15].

\section{Results and discussion}

Amplification and cloning of the S. pneumoniae alr gene The putative open reading frame for the alanine racemase from S. pneumoniae was identified through sequence comparison between known alanine racemase sequences and the S. pneumoniae sequences deposited in GenBank. There was only one unambiguous hit in the database (data not shown), suggesting that $S$. pneumoniae, unlike E. coli or $P$. aeruginosa, contains only one alanine racemase. The second alanine racemase (DadX) when present is commonly part of an operon. The $S$. pneumoniae genome carries only this single gene, not apparently in an operon, and thus is lacking the L-alanine inducible catabolic DadX alanine racemase. Using primers homologous to the $5^{\prime}$ and 3 ' end of the putative $a l r_{S P}$ an 1103 bp fragment was amplified and subsequently sequenced. The orf encodes a polypeptide of 367 amino acids with a calculated molecular weight of 39854 Daltons. Using the restriction sites incorporated into the PCR primers the gene was ligated into the expression vector gene pET17 and cloned in E. coli MB1547.

\section{Sequence analysis of Alr}

Comparison and analysis of the protein sequence encoded by $a l r_{s p}$ from strain R800 revealed full identity with the protein sequences from strains R6 (GenBank accession number: P0A2W9) and TIGR4 (GenBank accession number: AAK75776). Moreover, it displayed a high level of similarity with other alanine racemases (Fig. 1), and carried the expected motifs such as the characteristic pyridoxal phosphate binding site (VVKANAYGHG) near the $\mathrm{N}$-terminus, and the two catalytic amino acid residues (K40, Y263) of the active center [11]. Phylogenetic analysis (Fig. 2) revealed no surprises; the enzyme is clustered with other Streptococci species, such as $S$. mutans or $S$. pyogenes. These sequences, together with other alanine racemases from Gram-positive bacteria appear to occupy one half of the phylogenetic tree, while the Gram-negative bacteria occupy the other half.

Since both alanine racemase and certain human enzymes, such as serine racemase [16] depend on pyridoxal-5'phos- 


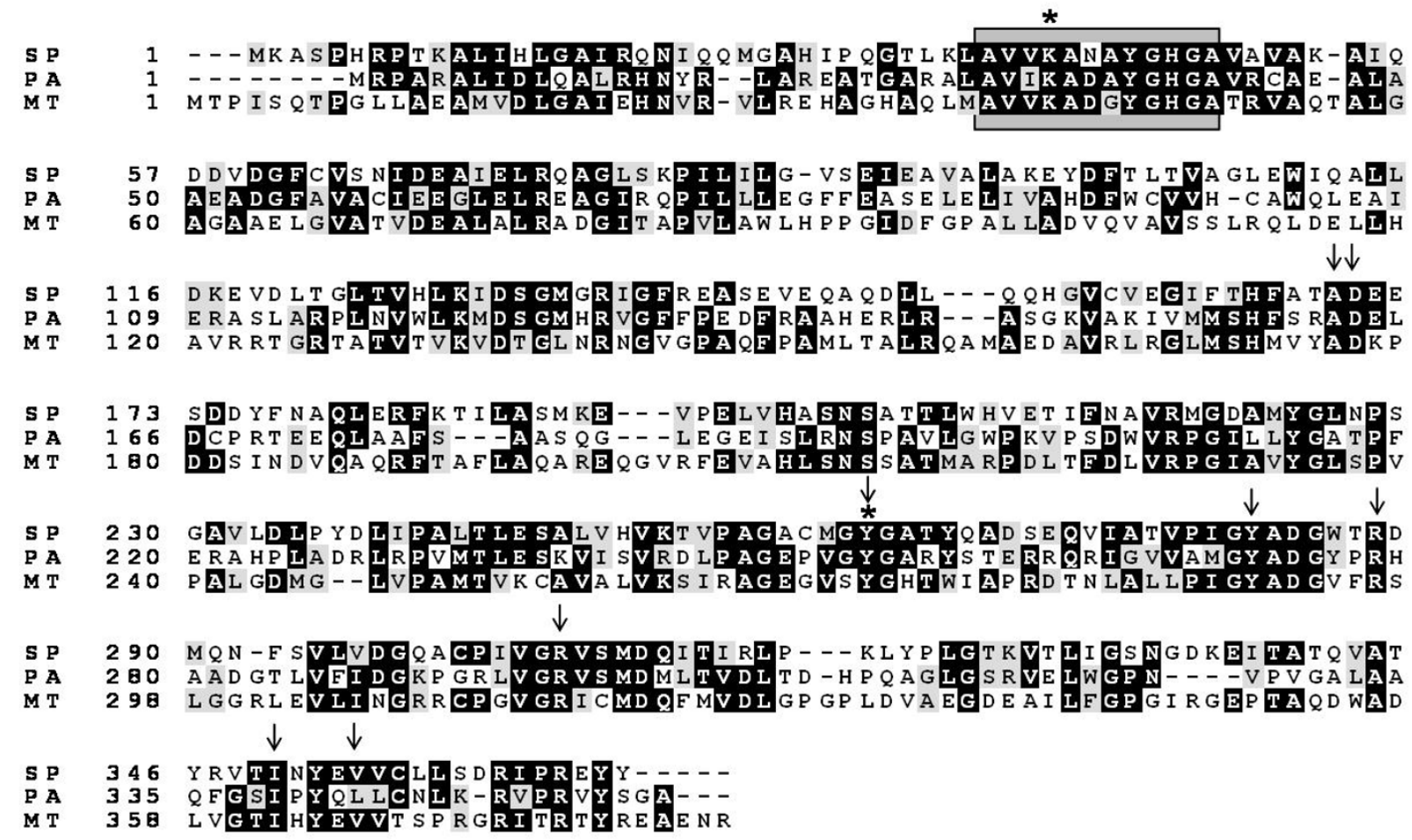

Figure I

ClustalW multiple sequence alignment of alanine racemases from S. pneumoniae (SP), P. aeruginosa DadX (PA) and M. tuberculosis (MT). The conserved pyridoxal 5'-phosphate binding site is boxed. An asterisk $\left(^{*}\right)$ is used to indicate the two catalytic residues, $\mathrm{K} 40$ and $\mathrm{Y} 263$. Arrows indicate eight conserved amino acid residues constituting the entryway to the active site [I I].

phate (PLP) as their co-factor, it is important that antibiotic design efforts aim to develop inhibitors that are specific for the bacterial enzyme. However, it is worth noting that, in the case of serine racemase and Alr $_{\mathrm{SP}}$ both enzymes are indeed significantly distinct. The two racemases are only $13 \%$ identical on the amino acid level, so while they both may still be inhibited by the same small molecule, there is significant diversity between the enzymes, making it more likely that a potential inhibitor will actually be alanine racemase specific. In addition, our drug design efforts extend well beyond the PLP binding site of the enzyme. As shown in our previous publication [11], alanine racemases are characterized by a geometrically distinct entryway to the active site that is made up of eight highly conserved amino acid residues. This entryway is fully conserved in the $\mathrm{Alr}_{\mathrm{SP}}$ sequence; residues $\mathrm{Y} 253$, Y352, Y282 and A169 form the inner layer, while residues R307, I350, R288 and A170 constitute the middle layer. Sequence analysis of the human serine racemase fails to identify those conserved residues. We thus hypothesize that an inhibitor designed to block the entryway would specifically inhibit the bacterial target, alanine racemase, and be much less likely to cross-react with eukaryotic PLPcontaining enzymes.

\section{Complementation analysis}

In vivo demonstration that the gene product expressed alanine racemase activity was shown by complementation. The D-alanine auxotrophic E. coli strain MB2795 was transformed with pET17-alr $r_{S P}$. A plasmid encoding the cloned $P$. aeruginosa DadX alanine racemase, pMB1921 was used as a positive control. pET17 without insert served as a negative control. Cells were plated on LB medium with and without D-alanine supplementation, and scored for colony growth after $16 \mathrm{~h}$ at $37^{\circ} \mathrm{C}$. The alanine racemase gene from $S$. pneumoniae fully restored the wild-type phenotype, as did the $P$. aeruginosa dadX plasmid. Cells transformed with pET17 failed to grow. Thus the cloned S. pneumoniae gene encodes a functional alanine racemase. 


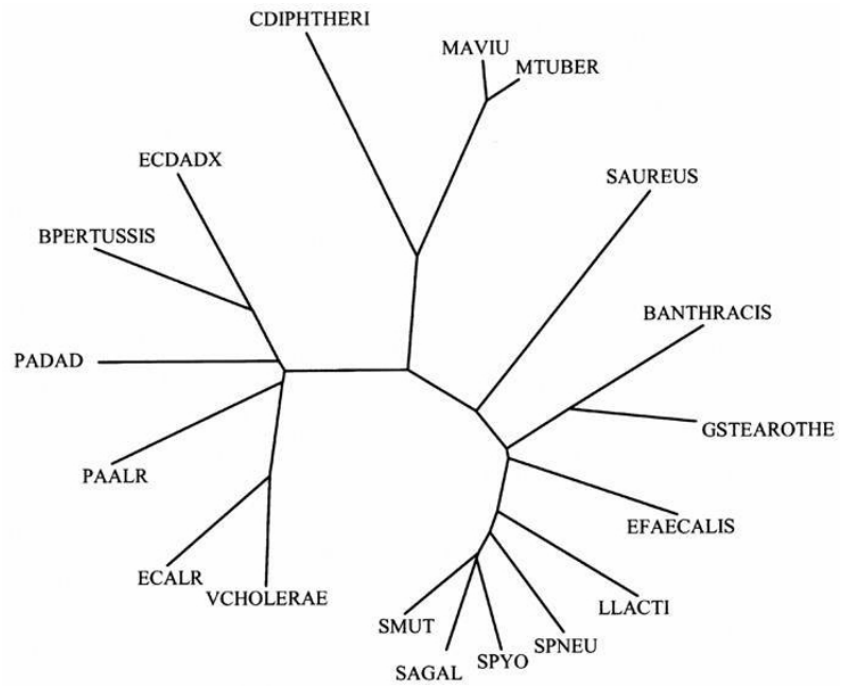

Figure 2

Phylogenetic tree of ALR based on amino acid sequences. The tree was constructed using the ClustalW and Phylip programs as described in Section 2.x.: VCHOLERAE (Vibrio cholerae, NP230026), ECALR (E. coli, NP4 18477), PAALR (Pseudomonas aeruginosa, AAD47082), PADADX (P. aeruginosa, AAD4708I), ECDADX (E. coli, NP4I 5708), BPERTUSSIS (Bordetella pertussis, NP879994), CDIPHTHERI (Corynebacterium diphtheriae, NP938944), MAVIUM (M. avium, AAF25943), MTUBER (M. tuberculosis, AAD5I033), BANTHRACIS (Bacillus anthracis, NP842805), GSTEAROTHE (Geobacillus stearothermophilus, PI0724), EFAECALIS (Enterococcus faecalis, NP8I459I), LLACTIS (Lactobacillus lactis, NP 267000), SPNEU (S. pneumoniae, AAD5 I027), SPYO (S. pyogenes, YP603085), SAGAL (S. agalactiae, NP688675), SMUT (S. mutans, NP722I5I).

\section{Overexpression, purification and biochemical characterization}

The recombinant pET17-alr $r_{S P}$ plasmid was transformed into E. coli BL21(DE3), pLysS, and expressed upon induction of T7 polymerase. The enzyme was purified to electrophoretic homogeneity as summarized in Table 1. Purified enzyme was obtained in an overall yield of $28.7 \%$ and exhibited a 12.9 fold increase in specific activity over the crude lysate. The molecular mass of the purified protein, estimated by SDS-PAGE analysis, was approximately $39 \mathrm{kDa}$, in line with the calculated value for the $a l r_{S P}$ open reading frame (Fig. 3). The kinetic properties of the purified $S$. pneumoniae enzyme are similar to other alanine racemases, it has a $K_{m}$ for D-alanine at $23^{\circ} \mathrm{C}$ of $2.10 \mathrm{mM}$ and for L-alanine of $1.92 \mathrm{mM}$. The $V_{\max }$ for the racemization (D- to L-alanine and L- to D-alanine) is 87.0 and 84.8 $\mathrm{U} \mathrm{mg}^{-1}$, respectively, where one unit was defined as the amount of enzyme that catalyzed racemization of $1 \mu \mathrm{mol}$ of substrate per minute. These values were used to calculate a $K_{e q}$ of 1.07 for this reaction, thus fulfilling the criterion $\left(K_{e q} \sim 1.0\right)$ for a chemically symmetric reaction [17].
Some recent data suggested that alanine racemases are either monomeric or dimeric [18]. Initially, molecular sieve chromatography was used to answer this question for $\mathrm{Alr}_{\mathrm{SP}}$. The molecular weight of five protein standards was plotted versus the ratio of their elution volume to the void volume of the column to yield a linear calibration curve. This curve was then used to determine an apparent molecular weight of 80000 Daltons for $\mathrm{Alr}_{\mathrm{SP}}$, a value suggesting a dimeric state for the enzyme. In order to further classify $\mathrm{Alr}_{\mathrm{SP}}$ we additionally performed dynamic light scattering using the Superdex purified enzyme. When tested at $1.8 \mathrm{mg} / \mathrm{ml}$ we observed a single peak with a hydrodynamic radius of $3.7 \mathrm{~nm}$ and a monodisperse profile. This radius corresponds to a molecular weight of 71000 Daltons, clearly suggesting that in solution the dominant form of $\mathrm{Alr}_{\mathrm{SP}}$ is the dimer. Even at lower concentrations of protein, we were not able to see any evidence for $\mathrm{Alr}_{\mathrm{SP}}$ monomers, nor did we observe any mixed populations of monomers and dimers in the same preparation. As a result we conclude that this enzyme belongs to the majority of alanine racemases that form dimers, as do the enzymes from M. tuberculosis [11] and P. aeruginosa [19].

\section{Preliminary crystallization}

Preliminary crystals for $\mathrm{Alr}_{\mathrm{SP}}$ were obtained using a sparse matrix crystallization approach [20]. Initial crystals were obtained in 1.4 M NaCitrate, 0.1 M Hepes, pH7.5. This condition was successively modified and better crystals of $0.25 \times 0.25 \times 0.1 \mathrm{~mm}$ were eventually obtained in $1.2 \mathrm{M}$ NaCitrate, 0.1 M MES, pH7.2, 10\% glycerol (Fig. 4). Data analysis using X-ray crystallography is underway.

\section{Conclusion}

We have isolated the gene encoding alanine racemase from $S$. pneumoniae and obtained high level heterologous expression in E. coli as a dimer of $80 \mathrm{kda}$. Sequence homology, complementation of a D-alanine auxotroph, and a specific spectrophotometric enzyme assay confirm the identity of the cloned protein. With the recent acquisition of protein crystals described here, and the homology with other known alanine racemases whose structures are available, we anticipate the structure of this enzyme should soon be available, allowing it to be integrated into our ongoing structure-based drug design project.

\section{Methods}

\section{Bacterial strains, plasmids and culture conditions}

E. coli MB1547 (supE thi hsd 45 (lac-proAB) endA $\mathrm{F}^{\prime}[\operatorname{traD} 36$ proAB lacIqlacZ $\left.\Delta M 15]\right)$ was used for routine cloning and molecular biology. E. coli MB2795 is an alanine racemase deficient double-mutant (alr::frt dadX::frt) of E. coli MG1655 that we routinely use to assess alanine racemase activity of cloned fragments from bacteria [21]. Overexpression of alanine racemase from $S$. pneu- 
Table I: Purification of alanine racemase from Streptococcus pneumoniae

\begin{tabular}{|c|c|c|c|c|c|}
\hline & Volume $[\mathrm{ml}]$ & Protein Conc $[\mathrm{mg} / \mathrm{ml}]$ & Total Protein [mg] & Specific Activity [u/mg] & Total Activity [u] \\
\hline Crude Extract & 90.00 & 12.50 & 1125.00 & 5.10 & 5736.54 \\
\hline Supernatant after $20 \% \mathrm{AmSO}_{4}$ precipitation & 95.00 & 8.90 & 845.50 & 6.33 & 5358.91 \\
\hline Resuspended pellet after $60 \% \mathrm{AmSO}_{4}$ precipitation & 35.00 & 22.50 & 787.50 & 6.74 & 5311.40 \\
\hline Before Q-Sepharose & 45.00 & 13.00 & 585.00 & 8.16 & 5143.09 \\
\hline After Q-Sepharose & 24.00 & 3.80 & 91.20 & 45.87 & 4174.49 \\
\hline After HIC & 10.00 & 7.00 & 70.00 & 49.91 & 3556.27 \\
\hline Before Superdex & 8.00 & 3.30 & 26.40 & 64.09 & 1692.09 \\
\hline After Superdex & 0.50 & 50.00 & 25.00 & 65.81 & 1645.23 \\
\hline
\end{tabular}

moniae was performed in E. coli BL21 (DE3), pLysS (Novagen). pET17 (Novagen) was the vector used for expression of the alr gene from S. pneumoniae. pMB1921, expressing the alanine racemase (DadX) from Pseudomonas aeruginosa [22], was used as a positive control in the complementation experiments. All cells were routinely grown in $\mathrm{LB}$ medium with $100 \mu \mathrm{g} / \mathrm{ml}$ ampicillin. E. coli BL21 (DE3), pLysS cultures also contained $30 \mu \mathrm{g} / \mathrm{ml}$ chloramphenicol.

\section{Gene cloning}

Plasmid pR283 [23] derived from S. pneumoniae R800 was used as template for PCR amplification. Two primers (5' CCCATATGAAAGCTAGTCCA CATAGACCAACC 3', 5' GGGGATCCTTTCTTTTCTAATAATATTCTCTCGG 3', underlined sequences represent NdeI and BamHI restriction sites, respectively) were designed based on sequence comparisons between known alanine racemase genes and the S. pneumoniae R6 sequence in GenBank [24]. Gene

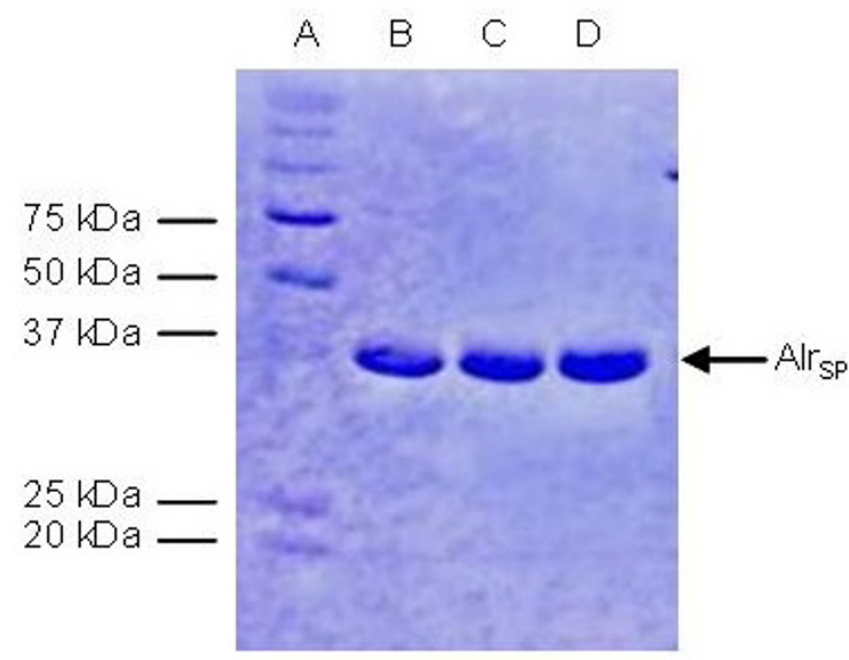

\section{Figure 3}

SDS-polyacrylamide gel electrophoresis of alanine racemase from S. pneumoniae (Lanes B-D) and protein molecular weight markers (Lane A, BioRad Dual Color Marker) stained with Coomassie blue. Lanes B-D represent the three peak fractions from the final gel filtration step. amplification was performed as described [22]. The PCR product was digested with $\mathrm{NdeI}$ and Bam HI and ligated into an appropriately cut pET17 vector, yielding pET17$a l r_{S P}$.

\section{Nucleotide sequencing}

DNA sequencing was performed on an ABI Prism 373 sequencer using the dye terminator cycle sequencing kit (Perkin-Elmer). Primers complementary to the T7 promoter and terminator regions were used to determine the sequence of the cloned fragment.

\section{Sequence analysis}

Nucleotide sequence comparisons were conducted at the NCBI website [25] using the Blast algorithm [26]. Multiple sequence alignments were performed using ClustalW [27] at the European Bioinformatics Institute [28] website. Phylogenetic relationships were investigated using

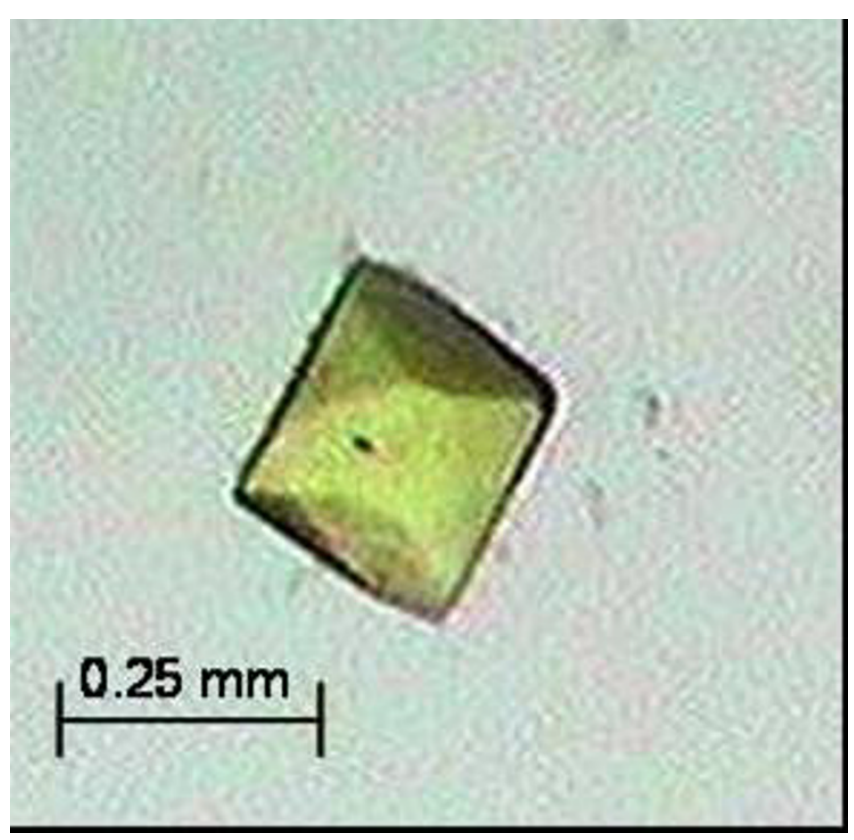

Figure 4

Alr $r_{\text {SP }}$ crystal $(0.25 \times 0.25 \times 0.1 \mathrm{~mm})$, obtained in a solution of I. $2 \mathrm{M} \mathrm{NaCitrate,} \mathrm{0.I} \mathrm{M} \mathrm{MES,} \mathrm{pH7.2,} \mathrm{I0 \%} \mathrm{glycerol,} \mathrm{by} \mathrm{using}$ the sitting vapor diffusion method. 
the Phylip software package [29] at the Pasteur Institute [30].

\section{Protein expression and purification}

E. coli BL21(DE3), harboring pET17-alr $r_{S P}$ pLysS was grown, induced and harvested as described [22]. The cell pellet from $6 \mathrm{l}$ of culture was initially suspended in $90 \mathrm{ml}$ $20 \mathrm{mM}$ Tris- $\mathrm{HCl}, \mathrm{pH} 8,0.5 \mathrm{mM}$ pyridoxal phosphate. After sonication $(6 \times 50 \mathrm{~W}$ for $20 \mathrm{sec})$ and centrifugation (JA20, $27000 \times \mathrm{g}, 25 \mathrm{~min})$, ammonium sulfate $\left.\left(\left(\mathrm{NH}_{4}\right)_{2} \mathrm{SO}_{4}\right)\right)$ was added to the supernatant to a final concentration of $20 \%$ saturation. The precipitate was removed by centrifugation (as above), and $\left(\mathrm{NH}_{4}\right)_{2} \mathrm{SO}_{4}$ was added to the supernatant to a final concentration of $60 \%$ saturation. After centrifugation (as above) the pellet was suspended in 35 $\mathrm{ml} 20 \mathrm{mM}$ Tris- $\mathrm{HCl}, \mathrm{pH} 8$, dialyzed against $20 \mathrm{mM}$ Tris$\mathrm{HCl}, \mathrm{pH} 8$, and purified over a Q-Sepharose High Performance column (GE Amersham) using a $0-1 \mathrm{M} \mathrm{NaCl}$ gradient in $20 \mathrm{mM}$ Tris- $\mathrm{HCl}, \mathrm{pH}$. The peak fractions were pooled, $\left(\mathrm{NH}_{4}\right)_{2} \mathrm{SO}_{4}$ was added to $1 \mathrm{M}$, and the sample was further purified through HiPrep Phenyl (low sub) hydrophobic interaction chromatography (GE Amersham) using a 1-0 $\mathrm{M}\left(\mathrm{NH}_{4}\right)_{2} \mathrm{SO}_{4}$ gradient. The peak fractions were pooled, dialyzed against $20 \mathrm{mM}$ Tris- $\mathrm{HCl}$, pH8, concentrated and loaded onto a Superdex 200 Prep Grade column (GE Amersham) for the final purification step and peak fractions were pooled and retained.

\section{Enzyme assay, characterization, and protein determination}

Throughout the purification quantity and quality of the preparation were monitored by assaying protein concentration [31] and enzyme activity [22]. The purification was further monitored using SDS-PAGE on a GE-Amersham PHAST gel system. The molecular weight of the native enzyme was estimated by comparing its migration on the Superdex 200 column with five protein standards (12-200 kDa) from the Sigma MWGF200 standards kit. Dynamic light scattering of a $1 \mathrm{mg} / \mathrm{ml}$ sample of $\mathrm{Alr}_{\mathrm{SP}}$ was done at $20^{\circ} \mathrm{C}$ using the DynaPro Titan system according to the manufacturer's instructions (Wyatt Technology). Prior to the measurements, all samples were spun in an Eppendorf 5415 tabletop centrifuge and then filtered through a 0.02 micron Whatman Anotop filter in order to remove aggregates prior to measurement of light scattering data.

\section{Crystallization}

$\mathrm{Alr}_{\mathrm{SP}}$ was crystallized at a concentration of $21 \mathrm{mg} / \mathrm{ml}$ using the sitting drop vapor diffusion method. $1 \mu \mathrm{l}$ of protein and $1 \mu \mathrm{l}$ of mother liquor were automatically mixed in a 96 well plate using the Honeybee 961 crystallization robot (Genomic Solutions). Each plate was set up at $4^{\circ} \mathrm{C}$ with the 96 conditions of the Crystal Screen HR2-130 kit
(Hampton Research). Image analysis was done by visual inspection.

\section{Sequence Accession Numbers}

The nucleotide and amino acid sequences of $\mathrm{ALR}_{\mathrm{SP}}$ have been submitted to GenBank under Accession Nos. $\underline{\text { AF171873 }}$ and $\underline{\text { ADD51027, }}$, respectively.

\section{Authors' contributions}

US was responsible for cloning and, in part, expression and biochemical characterization of the alanine racemase, and prepared the manuscript. MD and JLP performed the expression and purification of ALR, as well as the lightscattering experiments. EM and HI performed crystallization experiments. MJB and KLK supervised the work, organized financial support, and critically appraised the manuscript. All authors read and approved the final manuscript.

\section{Acknowledgements}

We thank Linda Guynn for technical assistance and members of our groups for helpful discussions. This work was supported by NIH grant Al46340 and the Robert A. Welch Foundation.

\section{References}

I. Jedrzejas MJ: Pneumococcal virulence factors: structure and function. Microbiol Mol Biol Rev 200I, 65(2):187-207; first page, table of contents.

2. File TM: Community-acquired pneumonia. Lancet 2003, 362(9400): $|99|-200 \mid$.

3. Hale KA, Isaacs D: Antibiotics in childhood pneumonia. Paediatr Respir Rev 2006, 7(2): I 45-15I.

4. Krause KL, Stager C, Gentry LO: Prevalence of penicillin-resistant pneumococci in Houston, Texas. Am J Clin Pathol 1982, 77(2):210-213.

5. File TM Jr.: Clinical implications and treatment of multiresistant Streptococcus pneumoniae pneumonia. Clin Microbiol Infect 2006, I2 Suppl 3:3I-4I.

6. Jacobs MR, Felmingham D, Appelbaum PC, Gruneberg RN: The Alexander Project 1998-2000: susceptibility of pathogens isolated from community-acquired respiratory tract infection to commonly used antimicrobial agents. I Antimicrob Chemother 2003, 52(2):229-246.

7. Doern GV, Richter SS, Miller A, Miller N, Rice C, Heilmann K, Beekmann S: Antimicrobial resistance among Streptococcus pneumoniae in the United States: have we begun to turn the corner on resistance to certain antimicrobial classes? Clin Infect Dis 2005, 4 I (2): 139-148.

8. Walsh C: Antibiotics : actions, origins, resistance. Washington, D.C. , ASM Press; 2003:x, 335 p..

9. Watanabe A, Yoshimura T, Mikami B, Esaki N: Tyrosine 265 of alanine racemase serves as a base abstracting alpha-hydrogen from L-alanine: the counterpart residue to lysine 39 specific to D-alanine. J Biochem (Tokyo) 1999, I 26(4):78I-786.

10. LeMagueres P, Im H, Dvorak A, Strych U, Benedik M, Krause KL: Crystal structure at I.45 A resolution of alanine racemase from a pathogenic bacterium, Pseudomonas aeruginosa, contains both internal and external aldimine forms. Biochemistry 2003, 42(50): | 4752-14761.

II. LeMagueres P, Im H, Ebalunode J, Strych U, Benedik MJ, Briggs JM, Kohn H, Krause KL: The I.9 A crystal structure of alanine racemase from Mycobacterium tuberculosis contains a conserved entryway into the active site. Biochemistry 2005, 44(5): |47|-|48I.

12. Kim MG, Strych U, Krause K, Benedik M, Kohn H: N(2)-substituted D,L-cycloserine derivatives: synthesis and evaluation as alanine racemase inhibitors. J Antibiot (Tokyo) 2003, 56(2): $160-168$. 
13. Kim MG, Strych U, Krause KL, Benedik MJ, Kohn H: Evaluation of amino-substituted heterocyclic derivatives as alanine racemase inhibitors. Med Chem Res 2003, I 2:130-138.

14. Available Chemicals Directory [http://www.accelrys.com]

15. Mustata GI, Briggs JM: A structure-based design approach for the identification of novel inhibitors: application to an alanine racemase. J Comput Aided Mol Des 2002, I 6( I 2):935-953.

16. Xia M, Liu Y, Figueroa DJ, Chiu CS, Wei N, Lawlor AM, Lu P, Sur C, Koblan KS, Connolly TM: Characterization and localization of a human serine racemase. Brain Res Mol Brain Res 2004, I 25(I2):96-104.

17. Briggs GE, Haldane JB: A Note on the Kinetics of Enzyme Action. Biochem J 1925, 19(2):338-339.

18. Yokoigawa $\mathrm{K}$, Okubo $\mathrm{Y}$, Soda K: Subunit interaction of monomeric alanine racemases from four Shigella species in catalytic reaction. FEMS Microbiol Lett 2003, 22 I (2):263-267.

19. Strych U, Benedik MJ: Mutant analysis shows that alanine racemases from Pseudomonas aeruginosa and Escherichia coli are dimeric. J Bacteriol 2002, 184(15):432I-4325.

20. Jancarik J, Kim SH: Sparse matrix sampling: a screening method for crystallization of proteins. Journal of applied crystallography I99I, 24:409-4II.

21. Strych U, Penland RL, Jimenez M, Krause KL, Benedik MJ: Characterization of the alanine racemases from two mycobacteria. FEMS Microbiol Lett 200I, 196(2):93-98.

22. Strych U, Huang HC, Krause KL, Benedik MJ: Characterization of the alanine racemases from Pseudomonas aeruginosa PAOI. Curr Microbiol 2000, 4 I (4):290-294.

23. Martin B, Sharples G], Humbert O, Lloyd RG, Claverys JP: The mmsA locus of Streptococcus pneumoniae encodes a RecG. like protein involved in DNA repair and in three-strand recombination. Mol Microbiol 1996, 19(5): 1035-1045.

24. Hoskins J, Alborn WE Jr., Arnold J, Blaszczak LC, Burgett S, DeHoff BS, Estrem ST, Fritz L, Fu DJ, Fuller W, Geringer C, Gilmour R, Glass JS, Khoja H, Kraft AR, Lagace RE, LeBlanc DJ, Lee LN, Lefkowitz EJ, Lu J, Matsushima P, McAhren SM, McHenney M, McLeaster K, Mundy CW, Nicas TI, Norris FH, O'Gara M, Peery RB, Robertson GT, Rockey P, Sun PM, Winkler ME, Yang Y, Young-Bellido M, Zhao G, Zook CA, Baltz RH, Jaskunas SR, Rosteck PR Jr., Skatrud PL, Glass Jl: Genome of the bacterium Streptococcus pneumoniae strain R6. J Bacteriol 200I, I 83( (19):5709-57/7.

25. NCBI [http://www.ncbi.nlm.nih.gov/BLAST/]

26. Altschul SF, Gish W, Miller W, Myers EW, Lipman DJ: Basic local alignment search tool. J Mol Biol 1990, 215(3):403-410.

27. Chenna R, Sugawara H, Koike T, Lopez R, Gibson T], Higgins DG, Thompson JD: Multiple sequence alignment with the Clustal series of programs. Nucleic Acids Res 2003, 3 I ( I 3):3497-3500.

28. European Bioinformatics Institute [http://www.ebi.ac.uk/clus talw]

29. Felsenstein J: PHYLIP (Phylogeny Inference Package). Department of Genetics, University of Washington, Seattle 1993.

30. Phylip at the Pasteur Institute [http://bioweb.pasteur.fr/seqanal/ interfaces/protdist-simple.html]

31. Bradford MM: A rapid and sensitive method for the quantitation of microgram quantities of protein utilizing the principle of protein-dye binding. Anal Biochem 1976, 72:248-254.

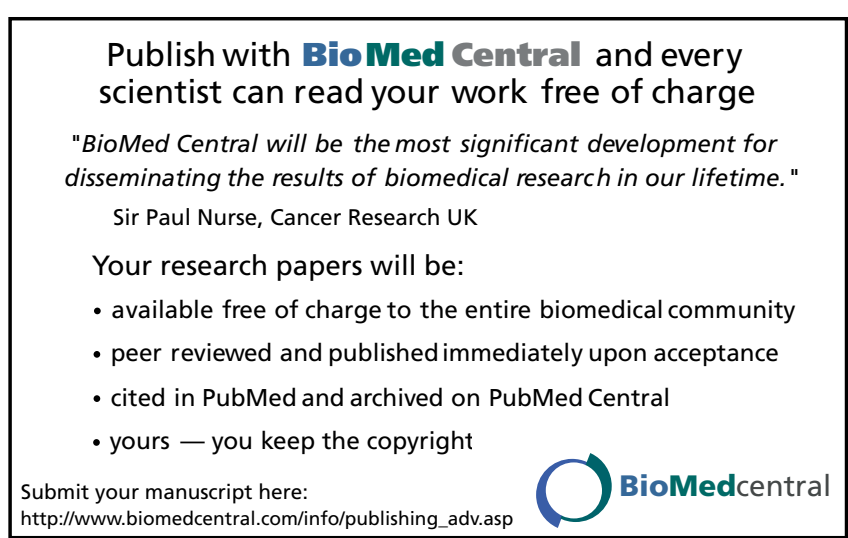

